\title{
Rapid Thermal Analysis of Nanocrystalline Inductors for Converter Optimization
}

DOI:

10.1109/JESTPE.2019.2947223

\section{Document Version}

Accepted author manuscript

Link to publication record in Manchester Research Explorer

\section{Citation for published version (APA):}

Scotlock, J., Wang, Y., Calderon-Lopez, G., \& Forsyth, A. (2019). Rapid Thermal Analysis of Nanocrystalline Inductors for Converter Optimization. IEEE Journal of Emerging and Selected Topics in Power Electronics. https://doi.org/10.1109/JESTPE.2019.2947223

\section{Published in:}

IEEE Journal of Emerging and Selected Topics in Power Electronics

\section{Citing this paper}

Please note that where the full-text provided on Manchester Research Explorer is the Author Accepted Manuscript or Proof version this may differ from the final Published version. If citing, it is advised that you check and use the publisher's definitive version.

\section{General rights}

Copyright and moral rights for the publications made accessible in the Research Explorer are retained by the authors and/or other copyright owners and it is a condition of accessing publications that users recognise and abide by the legal requirements associated with these rights.

\section{Takedown policy}

If you believe that this document breaches copyright please refer to the University of Manchester's Takedown Procedures [http://man.ac.uk/04Y6Bo] or contact uml.scholarlycommunications@manchester.ac.uk providing relevant details, so we can investigate your claim.

\section{OPEN ACCESS}




\title{
Rapid Thermal Analysis of Nanocrystalline Inductors for Converter Optimization
}

\author{
James Scoltock, Member, IEEE, Yiren Wang, Gerardo Calderon-Lopez, \\ and Andrew J. Forsyth, Senior Member, IEEE
}

\begin{abstract}
To capitalize fully on modern component technologies such as nanocrystalline cores and wide-bandgap devices, multi-objective converter design optimization is essential, requiring simple, accurate component models. In this work, a lumped parameter thermal model is presented for nanocrystalline inductors with ceramic heat spreaders. The key challenge is the non-uniform loss distribution in gapped, tape-wound cores, particularly the high loss densities adjacent to the gaps. However, uneven loss distributions are not handled easily by lumped-parameter techniques. It is shown that by treating the ceramic heat spreaders as 'passive' heat sources, a simple thermal model of the inductor can be derived to estimate the hot spot temperature of the core. The model is validated through comparison with 3-D finite element analysis (FEA) and experimental measurements on a $60 \mathrm{~kW}$ DC-DC converter. The proposed model offers a comparable level of accuracy to FEA with a fraction of the running time, executing in $99 \mu \mathrm{s}$ in MATLAB.
\end{abstract}

Index Terms - DC-DC converters, inductor design, inductor modelling, nanocrystalline magnetic materials, thermal modelling.

\section{INTRODUCTION}

To capitalize fully on modern component technologies such as nanocrystalline cores and wide-bandgap devices, converter design optimization has become increasingly important [1], balancing multiple design objectives such as power density and efficiency [2-4]. These techniques are reliant on multi-domain component models, including electrical, magnetic, and thermal behavior. The thermal domain is particularly important for high-frequency magnetic components since the internal temperature rise usually limits the component size [5]. Whilst FEA techniques can provide highly accurate temperature predictions, the execution time is usually prohibitive for design optimization where many solutions must be calculated rapidly to explore the design space [6].

Lumped parameter (LP) thermal modelling is the primary alternative to FEA, offering the advantages of relatively simple

This work was supported by the UK Engineering and Physical Sciences Research Council (EPSRC) National Centre for Power Electronics within the Converters Theme $[\mathrm{EP} / \mathrm{K} 035096 / 1]$ and Converter Architectures [EP/R004137/1].

J. Scoltock is with The University of Sheffield, Sheffield, S1 4DE, UK. (e-mail: j.scoltock@sheffield.ac.uk).

Y. Wang is with the Hardware Department, Zytek Automotive/Continental Engineering Services, WS13 8RY, UK (e-mail: yiren.wang@contiengineering.com).

G. Calderon-Lopez and A. J. Forsyth are with The University of Manchester, Manchester, M13 9PL UK (e-mail: \{gerardo.calderon-lopez, andrew.forsyth $\} @$ manchester.ac.uk). models that may be easily parameterized and solved rapidly [6]. Such models are ideally suited to design optimization. Amongst the recent work on LP modelling, [7] presents a thermal network for a pre-biased inductor with the losses in the LP model provided by an electromagnetic FEA. In [8] a generalized 3-D cuboidal element is proposed and demonstrated for an inductor. In [9], a mesh-based LP approach is demonstrated to offer very accurate temperature estimation. Within a design optimization framework, simple conductive and convective LP models were utilized in [10] and [11], respectively. In [12], a more detailed model based on the 3-D cuboidal element was utilized for the optimization of a permanent-magnet-inductor.

One limitation of LP models is the assumption of uniform loss distributions in each core and winding segment or cuboidal element. However, some newer magnetic materials such as amorphous metal and nanocrystalline types can suffer from highly localized losses around the air gaps, leading to local hot spots. The hot spots cannot be predicted easily by LP modelling without using very small cuboidal elements, which can lead to a large number of elements in a 3-D structure and long solution times.

Nanocrystalline tape-wound cores, such as Finemet [13] and Vitroperm [14], offer low core losses and high saturation flux densities, making them an attractive choice for power-dense converter designs [15]. However, due to the high electrical conductivities of the amorphous metal ribbon that forms the cores, intense heating can occur around air gaps in the magnetic circuit due to the perpendicular component of the fringe-field $[16,17]$. One way to reduce the hot spots in the core is through the use of high-thermal-conductivity heat spreaders placed around the gap [18], for example using aluminum nitride. Further, a number of methods have been proposed to reduce gap losses including the use of multiple smaller gaps around the magnetic circuit [19], cutting slits in the cores near the air gap [20], or splitting the core into several sub-cores placed side-by-side [21]. More complex sub-sectioning of the core has also been proposed [22]. Other approaches involve shaping the core edges around the air gap where a number of different profiles have been suggested [23, 24]. The disadvantage of these techniques is that they require custom core shapes and/or cutting/machining of the core, risking damage to the laminations and inter-lamination insulation, which may increase core losses [25]. Whilst the gap losses can be significantly reduced by these techniques, they are not completely eliminated and the possibility of localized heating around the gap is likely to remain, especially for larger gaps.

In this work, a LP thermal model is presented for the 
optimization of foil-wound, potted, nanocrystalline inductors with ceramic heat spreaders. By treating the heat spreaders, which tend to collect and redistribute the heat generated near the air gaps, as 'passive' heat sources, a relatively simple LP model is derived, which provides accurate hot-spot temperature predictions with straightforward calculations.

The inductor construction and loss mechanisms are introduced first, then the simplified LP model is presented, followed by performance validation against 3-D FEA simulation and experimental measurements using a $60 \mathrm{~kW}$ DC-DC converter.

\section{INDUCTOR DESIGN AND MODELLING}

\section{A. Inductor Description}

An exploded view of the inductor is shown in Fig. 1. The core is formed by two C-shaped core halves. The copper foil winding is split into two identical parts, which are wound around each of the side-limbs of the core. The two core halves are separated by a gap of $l_{g} / 2$, which is necessary to prevent saturation. The windings on each limb are spaced away from the core by at least $l_{g} / 2$ to limit the effect of the fringe field on the windings. The heat spreaders sit within the gap in each limb and are slightly larger than the core cross-section, their edges being as close as possible to the inner faces of the windings.

The heat spreaders have high thermal conductivity, but to prevent eddy current losses must have low electrical conductivity. Ceramic tiles such as aluminum nitride work well. The heat spreaders conduct the gap losses, which occur within 1-2 $\mathrm{mm}$ of the core edges, across the cross-sectional area of the core halves, and away from the core towards the windings. Due to their high thermal conductivity, the heat spreaders tend to equalize the temperature across the gap faces.

The inductor is potted in an aluminum can, which would be mounted on the converter heat sink, and the can is filled with thermally-conductive epoxy resin. The can has internal shoulders to provide close contact between the core and can, improving the heat flow from the core. Electrical insulation between the winding turns and between the core and can is provided using Kapton film.

\section{B. Loss Modelling}

The losses in the inductor comprise conduction losses in the foil windings, $P_{w}$, electromagnetic losses in the core, $P_{h}$, which include hysteresis losses, classical eddy current losses and

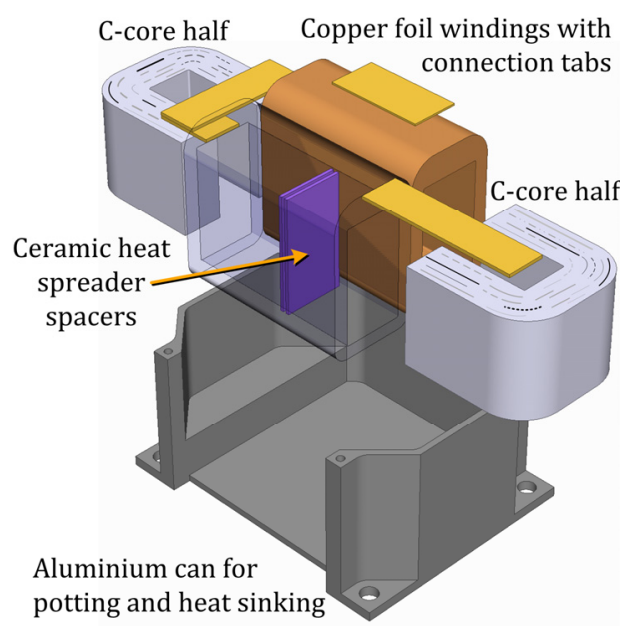

Fig. 1. Inductor assembly showing the core, winding, and heat spreader tiles within the gap. One side of the can is not shown to illustrate the shoulder at one end.

anomalous losses, and lastly gap losses, $P_{g}$. The gap losses are additional eddy current losses that occur in the core at the gap edges due to the fringing flux. The copper losses are modelled using the method presented in [26], which includes skin and proximity effects using a Dowell analysis. The core losses are modelled using a Steinmetz-type equation from manufacturer-provided data. The gap losses are modelled using the empirical formula in (1),

$$
P_{g}=k l_{g} F^{\alpha} B_{A C}^{\beta} D^{\gamma}
$$

where $F$ is the frequency, $B_{A C}$ is the AC flux density amplitude and $D$ is the core width. $k, \alpha, \beta$, and $\gamma$ are material-dependent constants. Values of the constants for Finemet material operating at high frequencies were determined by FEA in [16, 21 ], and the values used in this paper are $k=1.68 \times 10^{-3}, \alpha=1.72$, $\beta=2$ and $\gamma=1.65[16]$.

To illustrate the impact of gap losses and the effect of the heat spreaders on the temperature profile within a potted high frequency inductor, Fig. 2 shows FEA results. The inductor used a Finemet F3CC0032 core with three foil turns on each limb, $l_{g}=4.4 \mathrm{~mm}, F=60 \mathrm{kHz}, B_{A C}=0.16 \mathrm{~T}$, and a DC current of $160 \mathrm{~A}$. Under these conditions the gap loss accounted for $45 \%$ of the total component loss of $108 \mathrm{~W}$. Fig. 2(a) shows the gap loss density in the core, illustrating the high concentration of losses at the edges of the gap faces. Fig. 2(b) shows the corresponding temperature distribution in the core without heat

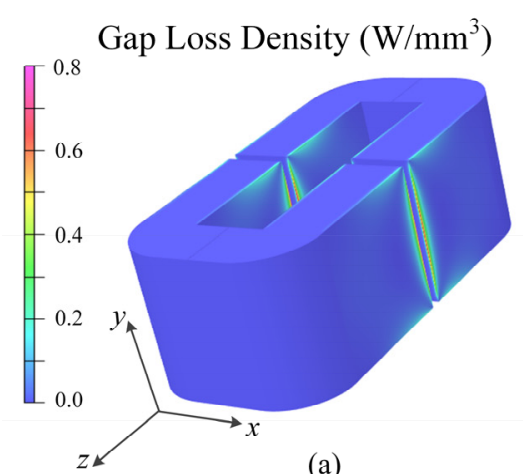

(a)

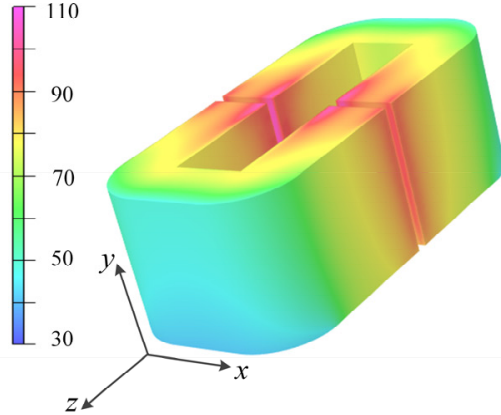

Temperature $\left({ }^{\circ} \mathrm{C}\right)$

Fig. 2. (a) Inductor gap loss density, (b) corresponding core temperature without and with heat spreaders.

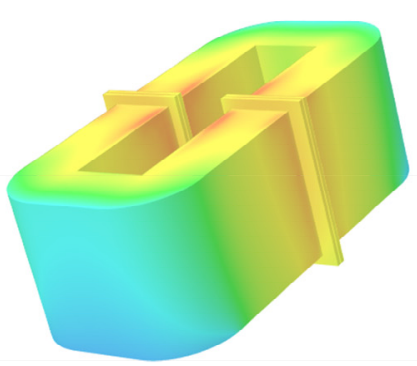

(b) 
spreaders (left), and with heat spreaders (right). The intense heating around the gap without heat spreaders is evident in Fig. 2(b), left, whilst the reduction in hot spot temperature with the heat spreaders, around $20^{\circ} \mathrm{C}$ is seen on the right.

\section{Thermal Model INCLUding Gap Losses AND HeAT SPREADERS}

By assuming that the potted inductor is symmetrical, the model is developed by considering one quarter of the component, as in Fig. 3. All the losses in the structure are removed by conduction through the base of the aluminum can.

To develop the model the inductor structure is represented by a number of cuboidal elements where the heat flow along each axis is modelled using a three-resistor network [8], as shown in Fig. 4(a). The internal heat source, $q$, is connected to the common node of the $x, y$, and $z$-axis networks. The temperature at the common node is the steady-state average temperature within the element, labelled $T_{a v}$ in Fig. 4(a). The expressions for the thermal resistances are derived in [8] by considering the solution to the one-dimensional heat flow problem in the presence of internal heat generation. The thermal resistances $R_{m l}$ to $R_{m 3}$ are,

$$
\begin{gathered}
R_{m 1}, R_{m 2}=\frac{l_{m}}{2 \kappa_{m} A_{m}}, \quad R_{m 3}=-\frac{l_{m}}{6 \kappa_{m} A_{m}}, \\
m \in\{x, y, z\}
\end{gathered}
$$

$R_{m 1}$ and $R_{m 2}$ account for the thermal resistance of the cuboid element along each axis, and they are correct when there is no internal heat generation. $R_{m 3}$ corrects the average temperature in the cuboid when there is an internal heat source, $q$, and its value is derived from the superposition of the solutions to the heat diffusion equation with and without internal heat generation [8]. Neglecting $R_{m 3}$ results in over-estimations of the average temperature. $T_{m 1}$ and $T_{m 2}$ are the surface temperatures of the cuboidal element, whilst $l_{m}, A_{m}$ and $\kappa_{m}$ denote the length, cross-sectional area and thermal conductivity of the element along axis $m$, as illustrated in Fig. 4(b) for the three axes.

\section{A. Derivation of the Proposed Model}

The model comprises four sections: the heat spreader, the core, the winding, and the encapsulation combined with the can. Each section is modelled by a cuboidal element of the form shown in Fig. 4(a). The parameters for all thermal resistances are provided in Appendix A.

Heat spreader: Due to its high thermal conductivity, the heat spreader tends to draw the gap loss from the core edges, distributing the heat across the face of the core and conducting it towards the windings. Furthermore since the heat spreader is very thin $(\approx 1 \mathrm{~mm})$ and its area is large, the effective thermal resistance in the z-axis is negligible and it can be modelled as a two-dimensional sheet having uniform temperature in the z-axis. The heat spreader thermal network is shown in Fig. 5, where the shading illustrates the outline of the core's cross sectional area, and the black frame indicates the edges of the heat spreader. A quarter of the total gap loss is split into two equal components, $P_{g} / 8$, which are assumed to be injected into

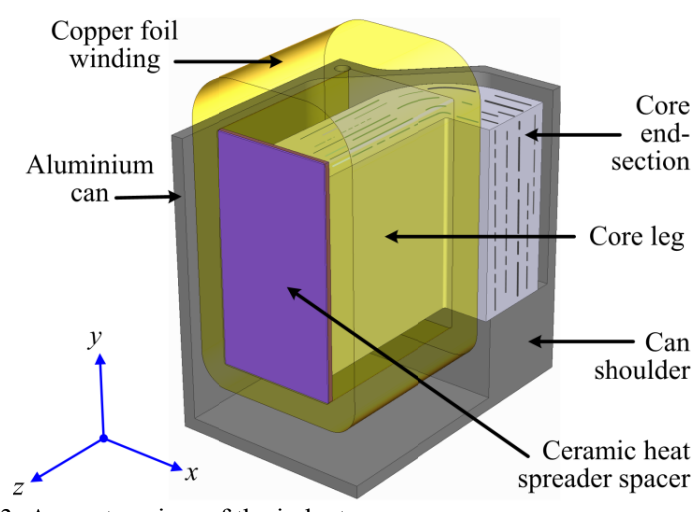

Fig. 3. A quarter-view of the inductor.

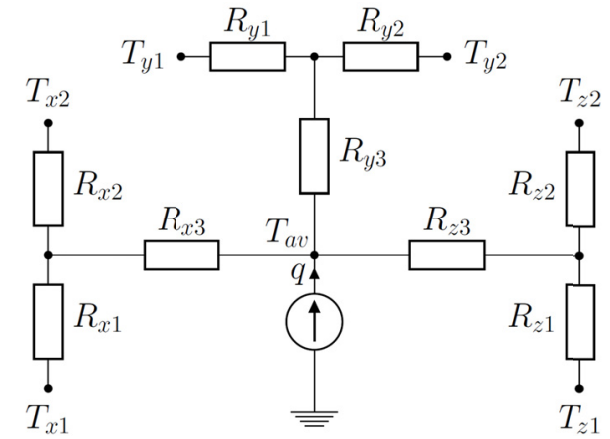

(a)

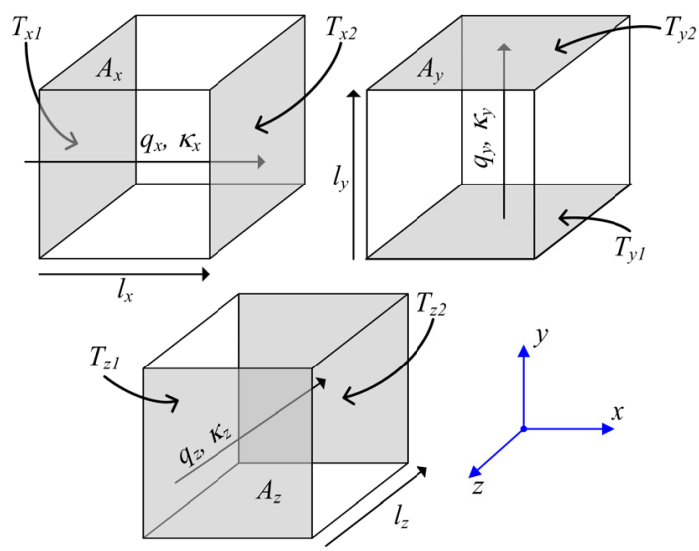

(b)

Fig. 4. Cuboidal element modeling. (a) Three-axis equivalent network, (b) cuboidal elements for the three axes.

the heat spreader adjacent to the outer and inner edges of the core face as external heat sources.

$T_{h s, x 1}$ and $T_{h s, x 2}$ denote the temperatures of the outer and inner edges of the heat spreader, whilst $T_{h s, y l}$ and $T_{h s, y 2}$ denote the temperatures of the top and bottom edges. The temperature at the center of the heat spreader is denoted $T_{g a p} . R_{h s, x l}-R_{h s, x 4}$ denote the $x$-axis thermal resistances; $R_{h s, x l}$ and $R_{h s, x 4}$ being those between the edges of the heat spreader and the edges of the core, and $R_{h s, x 2}$ and $R_{h s, x 3}$ are between the edges of the core and the center of the heat spreader. $R_{h s, y l}$ and $R_{h s, y 2}$ denote the $y$-axis thermal resistances. The heat flow in the $z$-axis, from the heat spreader into the potting compound, is assumed negligible. The maximum temperature is assumed to occur close to the inner edge of the core face, and is approximated by the adjacent point on the heat spreader, labelled $T_{\max }$ in Fig. 5.

Core: The heat within the core is assumed to flow from the 


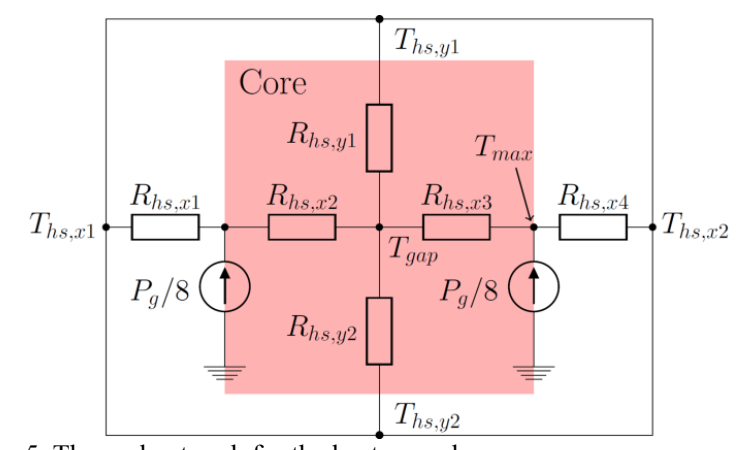

Fig. 5. Thermal network for the heat spreader.

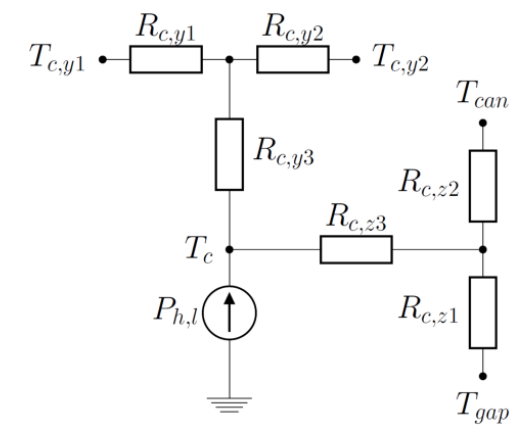

Fig. 6. Thermal network for the core leg.

core through the shoulders of the can, shown in Fig. 3, since this provides a high thermal conductivity path to the base of the can. Therefore the core end section temperature is assumed equal to that of the can shoulder and the loss within the end-section of the core is assumed to have a negligible effect on the hot-spot temperature. Due to the anisotropic thermal conductivity of the core, $<1 \mathrm{~W} / \mathrm{mK}$ through the laminations, but $10 \mathrm{~W} / \mathrm{mK}$ along the laminations, the heat flow in the core leg is assumed to be restricted to the $y$ - and $z$-axes, along the laminations.

Consequently, the core leg is modelled using the two-dimensional network in Fig. 6. $T_{c}$ is the average temperature of the core leg; $T_{c, y l}$ and $T_{c, y 2}$ are the temperatures of the top and bottom faces. The temperature at the center of the gap face is $T_{\text {gap }}$, that is the temperature at the center of the heat spreader. The temperature of the can shoulders, and therefore the end section of the core, is $T_{c a n}$. The uniformly distributed core loss is modelled by an internal heat source, $P_{h, 1}$.

Winding: The four sides of the foil winding $W_{I}-W_{4}$, as in Fig. 7 are each modelled as a cuboidal element, Fig. 8, where the index $m=1,2,3,4 . P_{w I}-P_{w 4}$ are the losses in each region, which are assumed uniform. The losses and thermal resistances of the rounded corner regions are assumed negligible.

The structure of the winding sections is illustrated in Fig. 7, giving rise to anisotropic thermal characteristics. Each region is homogenized by calculating an effective thermal conductivity in each axis from the weighted average of the thermal properties of the different materials. For the directions along the copper turns ( $x$ - and $z$-axes for $W_{l}$ and $W_{2}, y$-and $z$-axes for $W_{3}$ and $\left.W_{4}\right)$, the effective thermal conductivities are,

$$
\kappa_{\text {Along }}=\frac{\kappa_{C u} t_{C u}+\kappa_{\text {ins }} t_{\text {ins }}+\kappa_{\text {air }} t_{\text {pot }}}{t_{C u}+t_{\text {ins }}+t_{\text {pot }}}
$$

Through the windings, in the $y$-axis for $W_{1}$ and $W_{2}$, and $x$-axis for $W_{3}$ and $W_{4}$, the conductivities are

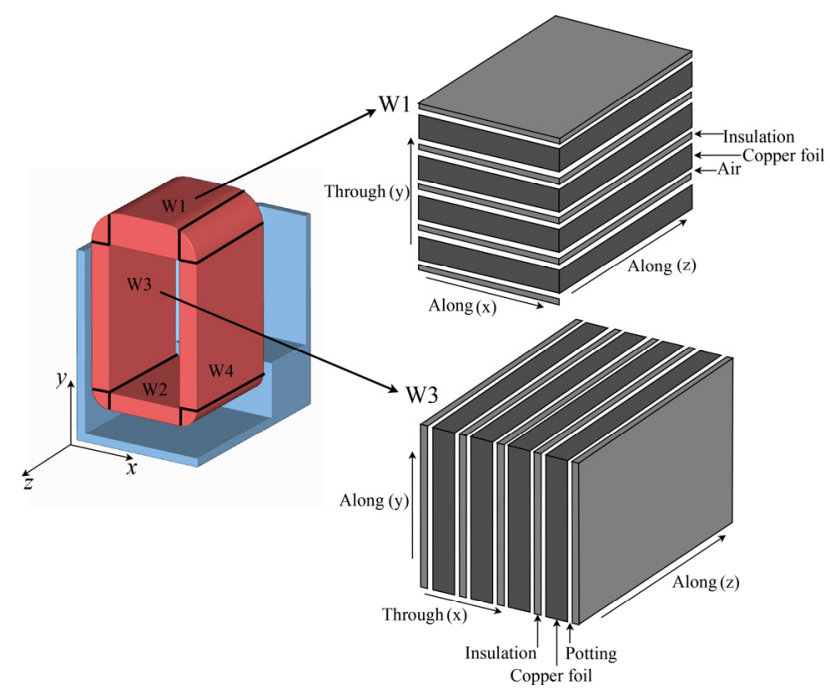

Fig. 7. Inductor winding and can showing the regions for thermal modelling, with views of $W_{l}$ and $W_{3}$ showing the layers of copper foil, insulation, and air/potting.

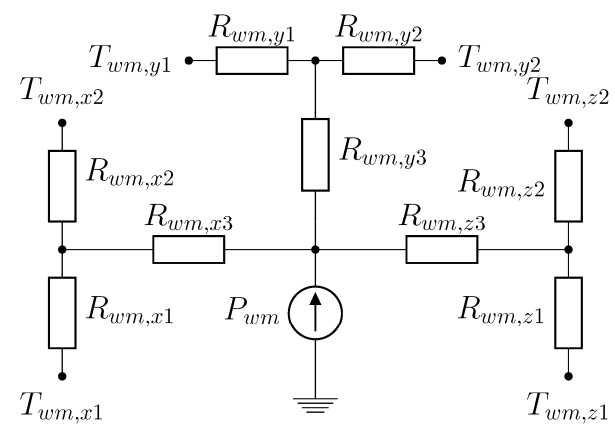

Fig. 8. Thermal network for winding regions $W_{1}-W_{4}$.

$\kappa_{\text {Through }}=\frac{\kappa_{C u} \kappa_{\text {ins }} \kappa_{\text {pot }}\left(t_{C u}+t_{\text {ins }}+t_{\text {pot }}\right)}{\kappa_{\text {ins }} \kappa_{\text {pot }} t_{C u}+\kappa_{C u} \kappa_{\text {pot }} t_{\text {ins }}+\kappa_{C u} \kappa_{\text {ins }} t_{\text {pot }}}$

$t_{C u}$ and $\kappa_{C u}$ are the thickness and thermal conductivity of each layer of copper foil, $t_{i n s}$ and $\kappa_{i n s}$ the thickness and thermal conductivity of each layer of insulation, and $t_{p o t}$ and $\kappa_{p o t}$ the thickness and thermal conductivity of each layer of potting material. Due to the very high thermal conductivity of copper, and the low thermal conductivities of the potting material and insulation, $\kappa_{\text {Along }}>>\kappa_{\text {Through }}$. Since $W_{l}$ is outside the potted part of the inductor structure, the space between the winding turns in this section is occupied by air instead of potting material, and the effective thermal properties are calculated by substituting $\kappa_{p o t}$ and $t_{p o t}$ with $\kappa_{\text {air }}$ and $t_{a i r}$ in (3) and (4).

In Fig. 8, $T_{w m, x l}$ and $T_{w m, x z}$, and $T_{w m, y l}$ and $T_{w m, y 2}$, denote the temperatures of the left, right, top and bottom, faces of each region. $T_{w m, z l}$ denotes the temperature of the 'end face' of each region, at the end of the winding towards the can, and $T_{w m, z 2}$ denotes the temperature of the 'symmetry face' of each region in the $z$-axis (the faces pointing out of the page in Fig. 7).

$R_{w m, x I}-R_{w m, x 3}, R_{w m, y l}-R_{w m, y 3}$, and $R_{w m, z}-R_{w m, z 3}$, denote the thermal resistances of each region in the $x$-, $y$-, and $z$-axes, respectively.

Encapsulation, Boundary Conditions and the Complete Model: The overall thermal model, as shown in Fig. 9, is produced by combining the thermal networks for the heat spreader, core and windings, Figs. 5, 6 and 8, with 


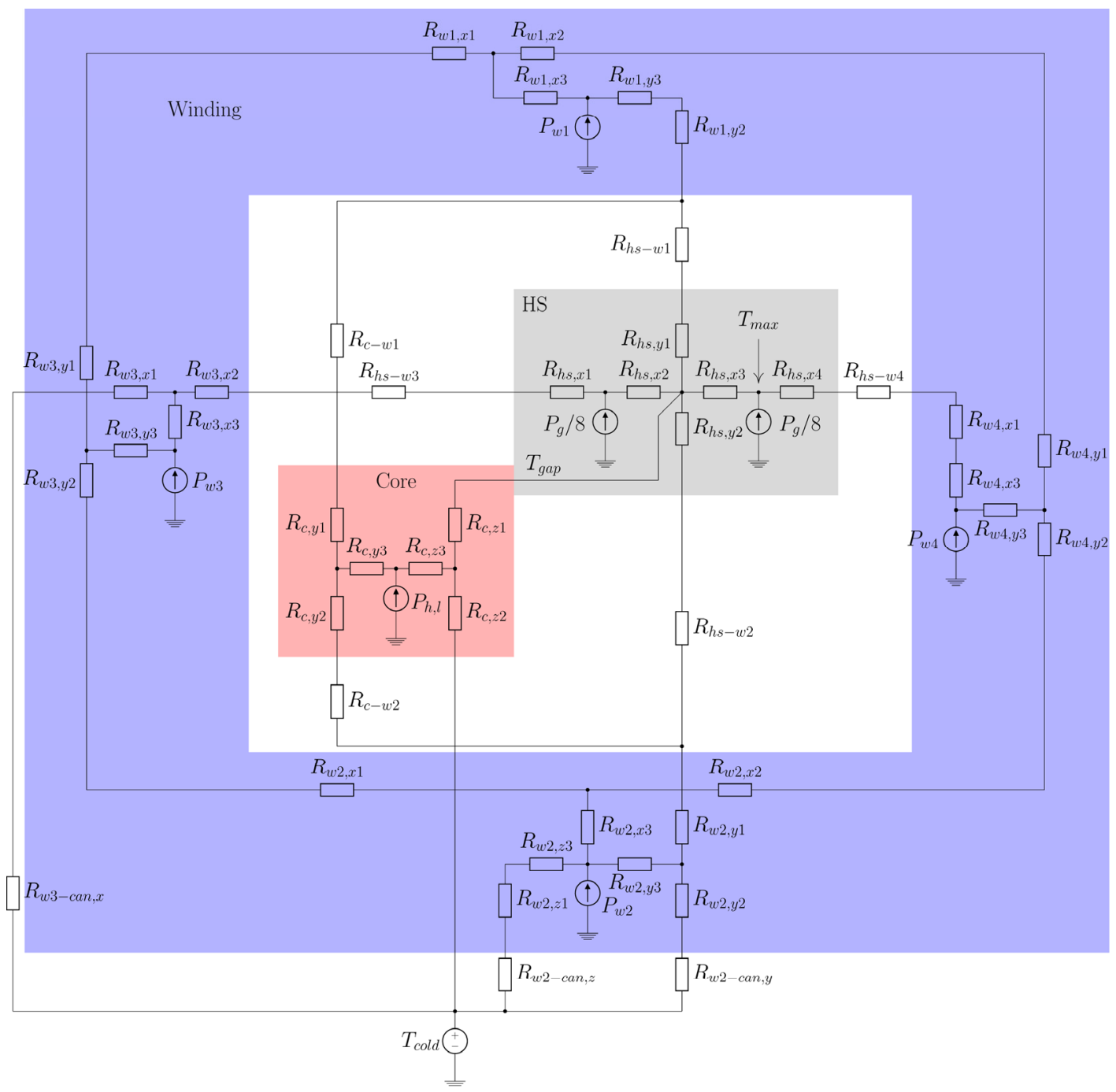

Fig. 9. Lumped-parameter thermal network for the inductor.

interconnections through the potting material. The heat flow through the potting material is modelled using one-dimensional thermal resistors as follows:

- between the edges of the heat spreader and the winding sections, $W_{l}-W_{4},\left(R_{h s-w l}-R_{h s-w 4}\right)$

- between the upper and lower faces of the core leg and winding sections $W_{l}$ and $W_{2},\left(R_{c-w l}\right.$ and $\left.R_{c-w 2}\right)$

- $\quad$ between the outer surfaces of winding sections $W_{2}$ and $W_{3}$ and the can, $\left(R_{w 2-c a n, y}\right.$ and $\left.R_{w 3-c a n, x}\right)$

- between the end face of winding section $W_{2}$ and the side of the internal shoulder in the can, $\left(R_{w 2-c a n, z}\right)$

Due to the high thermal conductivity of aluminum, the temperature of the can is assumed to be uniform and equal to the temperature of the cold surface, $T_{\text {cold }}$.

All external surfaces of the quarter-section inductor, Fig. 3, apart from the base of the can, are assumed to have no heat flow and are represented by adiabatic walls. For the cut faces of the quarter inductor this is due to the symmetry of the model, whilst for the outside faces convective heat flow is neglected. Consequently, several of the thermal resistors are omitted from the final model, these are $R_{w 1, y 1}, R_{w 4, x 2}, R_{w 1, z 2}-R_{w 4, z 2}$, and $R_{w m, z 1}$.

The thermal network can be reduced to a circuit with 18 nodes by combining series resistances and removing thermal resistances connecting to adiabatic boundaries where possible, and the steady-state core hot-spot temperature $T_{\max }$ can then be found by using standard circuit analysis techniques.

\section{MODEL VALIDATION}

Validation tests were undertaken by comparison of the predicted hot spot temperature from the LP model with values from a 3D FEA solution and measured data from an experimental prototype. The prototype used a Finemet F3CC0032 tape-wound core and was assembled as in Fig. 1. A 4-mm gap was included in the magnetic circuit by spacing the two U-shaped core halves apart by $2 \mathrm{~mm}$.

The winding comprised six turns of $0.6 \mathrm{~mm}$ copper foil, with three turns on each core leg. The winding was spaced away from the core by about $2.9 \mathrm{~mm}$. Aluminum nitride heat spreaders, 1-mm thick, were placed on the gap faces of the core halves with the heat spreaders extending beyond the edge of the core by $2 \mathrm{~mm}$. The complete inductor was mounted in an aluminum can and potted under vacuum conditions using a thermally conductive epoxy $(2.1 \mathrm{~W} / \mathrm{mK})$. The component had an inductance of $5.2 \mu \mathrm{H}$ and was designed to operate with a continuous current of 200 A with up to 80 A ripple current at $150 \mathrm{kHz}$. The inductor was designed for a $750 \mathrm{~V}, 60 \mathrm{~kW} \mathrm{SiC}$ DC-DC converter and was tested within the converter. Fig. 10 shows a photo of the complete component mounted on a calibrated heatsink, whilst Fig. 11 shows the placement of 


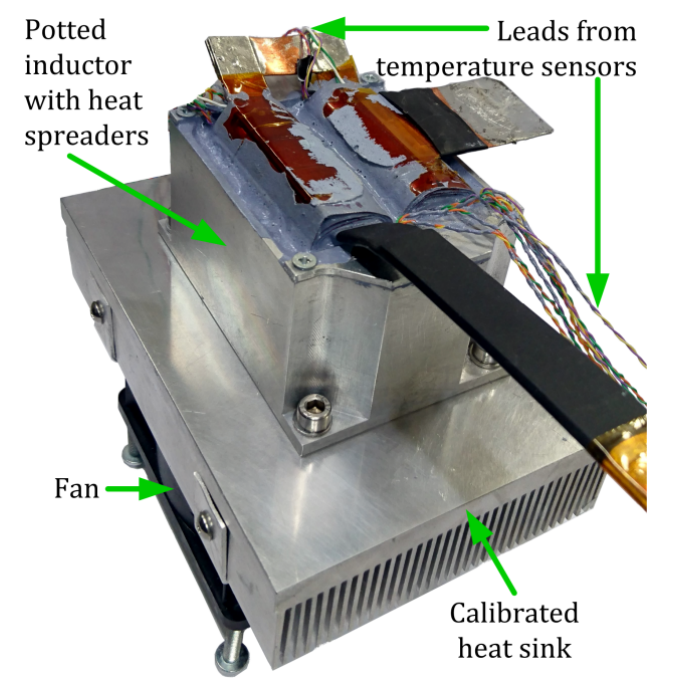

Fig. 10. Potted inductor mounted on a calibrated heat sink.

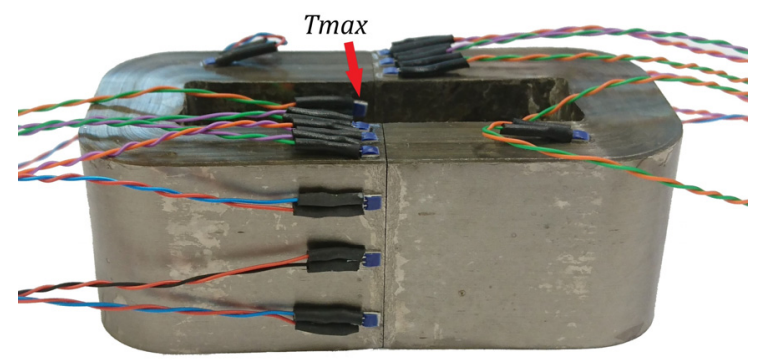

Fig. 11. The F3CC0032 inductor core with temperature sensors attached. The assumed maximum temperature rise was taken from the sensor labelled $T_{\max }$.

resistive temperature sensors on the cores. The overall loss in the experimental prototype was confirmed by measurement of the temperature rise of the calibrated heat sink shown in Fig. 10, which had a thermal resistance of $0.12{ }^{\circ} \mathrm{C} / \mathrm{W}$. During the tests the inductor was covered with insulating material to ensure all the heat was removed through the heat sink.

Table I summarizes the four different test conditions used in the experiments, which cover a range of losses and loss distributions within the inductor. Fig. 12 shows the predicted and measured losses for each condition, confirming the accuracy of the loss estimates. To account for the non-sinusoidal voltage waveforms in the inductor, the core losses were estimated with the Natural Steinmetz Extension (NSE) method [27] using the parameter values of $k_{\text {core }}=1.35$, $\alpha_{\text {core }}=1.6969$, and $\beta_{\text {core }}=1.9982,-$ which were determined from the manufacturer's loss data, the ratio of $k_{N} / k_{\text {core }}=0.082$ [27], and the $B_{A C}$ flux density is provided in Table I. The inductor was operated over 40 minutes in each condition to ensure thermal equilibrium. The maximum cold plate temperature was $52{ }^{\circ} \mathrm{C}$. Fig. 13 compares the temperature rise of the hot spot relative to the cold plate from the experimental prototype, the FEA solution and the proposed LP model.

For the four operating conditions considered, the FEA has average nominal and relative errors of $4.8{ }^{\circ} \mathrm{C}$ and $7.1 \%$ compared to the measured values, whilst the proposed LP model has average errors of $7.8^{\circ} \mathrm{C}$ and $13.1 \%$ compared to the measured values. This indicates that despite being far less computationally demanding, the accuracy of the proposed
TABLE I

OPERATING CONDITIONS FOR EXPERIMENTAL VALIDATION

\begin{tabular}{|c|c|c|c|c|}
\hline $\begin{array}{c}\text { Condition } \\
\text { No. }\end{array}$ & $\begin{array}{l}I_{D C} \\
(\mathrm{~A})\end{array}$ & $\begin{array}{l}I_{A C} \\
(\mathrm{~A})\end{array}$ & $\begin{array}{c}F \\
(\mathrm{kHz})\end{array}$ & $\begin{array}{l}B_{A C} \\
(\mathrm{~T}) \\
\end{array}$ \\
\hline 1 & 150 & 58 & 180 & 0.086 \\
\hline 2 & 160 & 45 & 148 & 0.068 \\
\hline 3 & 160 & 76 & 148 & 0.11 \\
\hline 4 & 160 & 86 & 148 & 0.13 \\
\hline
\end{tabular}

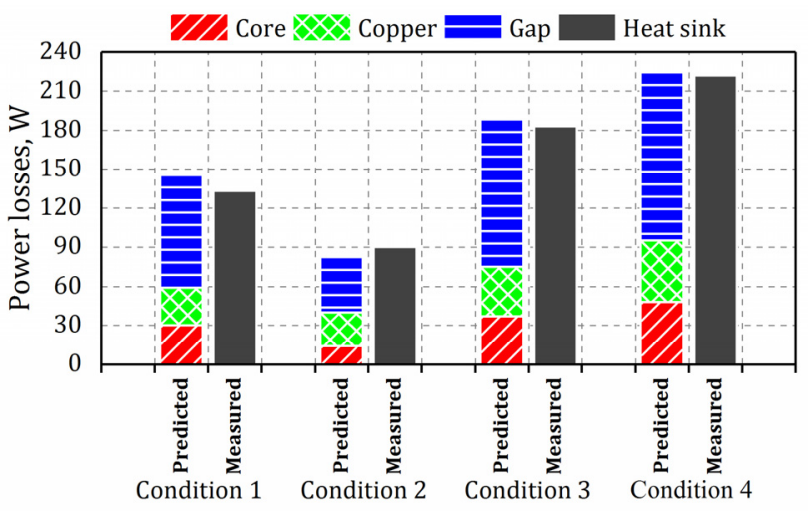

Fig. 12. Predicted and measured losses for the four operating conditions.

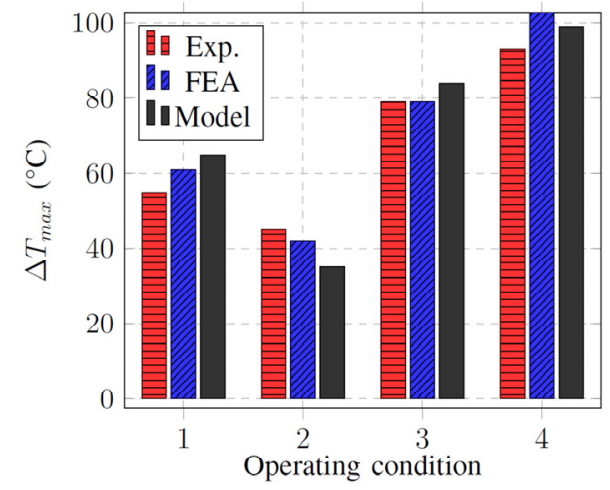

Fig. 13. Temperature rise for the four different operating conditions for prototype inductor.

model in estimating the hot-spot temperature is very good. With a core mesh size of $0.2 \mathrm{~mm}$, the steady-state thermal FEA took in the range of 20-30 minutes to find a solution, whilst the preceding electromagnetic FEA, meshing, and mesh transfer took 8-10 hours. Conversely, the proposed LP model can be executed very rapidly, taking on average $99 \mu$ s to execute.

Fig. 14 shows the temperature rise above the heat sink recorded at the temperature sensor $T_{\max }, \Delta T_{\max }$, and the temperature rise in the heat sink above the ambient, $\Delta T_{h s k}$, for operating condition 4 , demonstrating that the inductor and heat sink reached thermal equilibrium. Similar plots were observed for the other conditions.

Further validation of the model was undertaken using 3-D FEA results for two other inductor designs which use different (smaller) size cores, but are assumed to be constructed in a similar way to the experimental prototype. These two designs were produced as part of a design optimization study for two different $600 \mathrm{~V} \mathrm{DC}$-DC converters, the first rated at $20 \mathrm{~kW}$ and the second rated at $50 \mathrm{~kW}$. Table II summarizes the two designs. Table III lists the calculated power losses in the two designs under the operating condition that was analyzed, whilst Fig. 15 shows the comparison of the predicted hot spot 


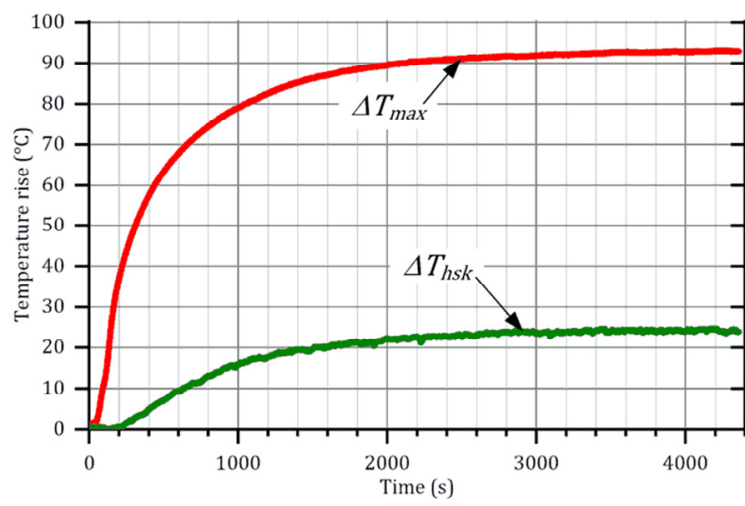

Fig. 14. Measured temperature rise at the hot-spot sensor, $T_{\max }$. and on the heat sink for operating condition 4

TABLE II

INDUCTOR DESIGNS AND OPERATING CONDITIONS FOR COMPARISON OF FEA AND LP MODELS

\begin{tabular}{lccc}
\hline \hline \multicolumn{1}{c}{ Parameter } & Design 1 & Design 2 & Unit \\
\hline Core part number & F3CC0010 & F3CC0016B & - \\
Number of turns, $N_{t}$ & 6 & 6 & - \\
Copper-foil thickness, $t_{C u}$ & 0.3 & 0.6 & $\mathrm{~mm}$ \\
Length of gap, $l_{g}$ & 2 & 4 & $\mathrm{~mm}$ \\
Nominal inductance, $L$ & 6.1 & 4.6 & $\mu \mathrm{H}$ \\
Frequency, $F$ & 300 & 240 & $\mathrm{kHz}$ \\
DC current, $I_{D C}$ & 91 & 227 & $\mathrm{~A}$ \\
AC ripple current, $I_{A C}$ & 16 & 27 & $\mathrm{~A}$ \\
AC flux, $B_{A C}$ & 0.165 & 0.096 & $\mathrm{~T}$ \\
\hline \hline
\end{tabular}

TABLE III

POWER LOSSES OF THE DESIGNS

\begin{tabular}{lccc}
\hline \hline \multicolumn{1}{c}{ Losses } & Design 1 & Design 2 & Unit \\
\hline Gap, $P_{g}$ & 33 & 75 & $\mathrm{~W}$ \\
Core, $P_{h}$ & 39 & 38 & $\mathrm{~W}$ \\
Winding, $P_{w}$ & 17 & 44 & $\mathrm{~W}$ \\
Total & 89 & 157 & $\mathrm{~W}$ \\
\hline
\end{tabular}

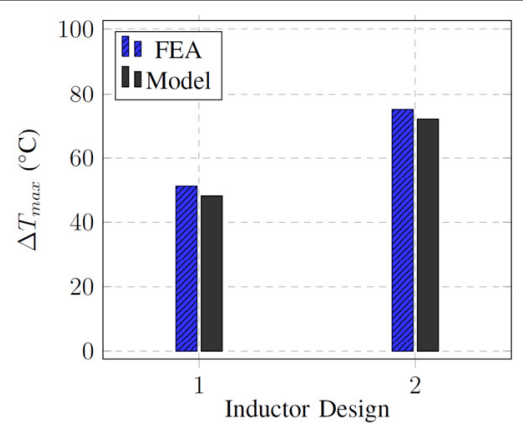

Fig. 15. Temperature rises for Inductor Designs 1 and 2.

temperature with the FEA data. Good correspondence is seen, with errors of $5.9 \%$ and $4 \%$, respectively. These results further confirm the effectiveness of the LP model in providing a rapid estimation of the internal hot-spot temperature rise.

\section{CONCLUSIONS}

This paper has presented a lumped parameter thermal model for nanocrystalline inductors with ceramic heat spreaders, suitable for converter design optimization. The model provides an estimate of the steady-state hot-spot temperature of the inductor core. The key challenge in the development of the model was the non-uniform loss distribution in the nanocrystalline inductor cores due to high eddy current losses adjacent to the air gaps. By treating the ceramic heat spreaders, which have a tendency to collect and redistribute the heat generated near the air gaps, as 'passive' heat sources, a relatively simple model was derived.

The model was validated through comparison with FEA and experimental results using an inductor with embedded temperature sensors within a $60 \mathrm{~kW}$ DC-DC converter. Over four different operating conditions, the estimated hot-spot temperature rise of the proposed model gave an average error of $13.1 \%$ relative to the experimentally measured values, which is very good considering the average error of $7.1 \%$ that was given by FEA. Further validation was provided by comparison of the estimated temperature rise with FEA results for two other inductor designs, which were generated as design optimization case studies, the relative error being less than $6 \%$.

Overall, the results indicate the effectiveness of the proposed LP model in estimating the hot-spot temperature of nanocrystalline inductor cores for rapid converter design optimization. The model demonstrates good agreement with FEA despite requiring only a fraction of the running time, executing in $99 \mu$ s when implemented in MATLAB, using a PC with average computing power. The approach could also be applied to other magnetic components where localized heating is an issue, for example due to gap losses in amorphous metal and other laminated cores, and could be readily extended to incorporate different heat spreader structures and winding arrangements within potted magnetic components. The potential importance of the technique in enabling rapid searches for optimum designs is indicated by the large proportion of a converter's weight, up to $50 \%$ in some cases, which is typically taken up by magnetic components.

\section{APPENDIX A}

The dimensions and thermal parameters for the experimental prototype are provided in Table IV. Dimensions $a-f$ are for the core, Fig. 16. Dimensions $l_{w 2-c a n}$ and $l_{w 3-c a n}$ denote the spacings

TABLE IV

MODEL DIMENSIONS AND THERMAL PARAMETERS FOR THE EXPERIMENTAL PROTOTYPE

\begin{tabular}{ll}
\hline \hline \multicolumn{2}{l}{ F3CC0032 core dimensions } \\
\hline$a=13 \mathrm{~mm}$ & $b=30 \mathrm{~mm}$ \\
$c=15 \mathrm{~mm}$ & $d=41 \mathrm{~mm}$ \\
$e=56 \mathrm{~mm}$ & $f=82 \mathrm{~mm}$ \\
\hline Winding features & \\
\hline$N_{t}=6$ & $t_{c u}=0.60 \mathrm{~mm}$ \\
$T_{i}=0.13 \mathrm{~mm}$ & $K_{w}=0.7$ \\
\hline \multicolumn{2}{l}{ Heat spreader dimensions } \\
\hline$T_{h s}=1.0 \mathrm{~mm}$ & \\
\hline Spacings & \\
\hline$l_{c-w l}=2.8 \mathrm{~mm}$ & $l_{c-w 2}=2.2 \mathrm{~mm}$ \\
$l_{c-w 3}=3.0 \mathrm{~mm}$ & $l_{c-w 4}=2.6 \mathrm{~mm}$ \\
$l_{h s-w l}=2.8 \mathrm{~mm}$ & $l_{h s-w 2}=2.2 \mathrm{~mm}$ \\
$l_{h s-w 3}=3.0 \mathrm{~mm}$ & $l_{h s-w 4}=2.6 \mathrm{~mm}$ \\
$l_{w 2-c a n, y}=2.0 \mathrm{~mm}$ & $l_{w 2-c a n, z}=2.0 \mathrm{~mm}$ \\
$l_{w 3-c a n, x}=3.0 \mathrm{~mm}$ & \\
\hline Thermal conductivities \\
\hline$\kappa_{c, y}=10 \mathrm{~W} / \mathrm{mK}$ & $\kappa_{c, z}=10 \mathrm{~W} / \mathrm{mK}$ \\
$\kappa_{w l, x}=209 \mathrm{~W} / \mathrm{mK}$ & $\kappa_{w l, y}=0.07 \mathrm{~W} / \mathrm{mK}$ \\
$\kappa_{w 2, x}=219 \mathrm{~W} / \mathrm{mK}$ & $\kappa_{w 2, y}=0.70 \mathrm{~W} / \mathrm{mK}$ \\
$\kappa_{w 2, z}=219 \mathrm{~W} / \mathrm{mK}$ & \\
$\kappa_{w 3, x}=0.70 \mathrm{~W} / \mathrm{mK}$ & $\kappa_{w 3, y}=219 \mathrm{~W} / \mathrm{mK}$ \\
$\kappa_{w 4, x}=0.70 \mathrm{~W} / \mathrm{mK}$ & $\kappa_{w 4, y}=219 \mathrm{~W} / \mathrm{mK}$ \\
$\kappa_{h s}=92 \mathrm{~W} / \mathrm{mK}$ & $\kappa_{p o t}=2.1 \mathrm{~W} / \mathrm{mK}$ \\
\hline
\end{tabular}




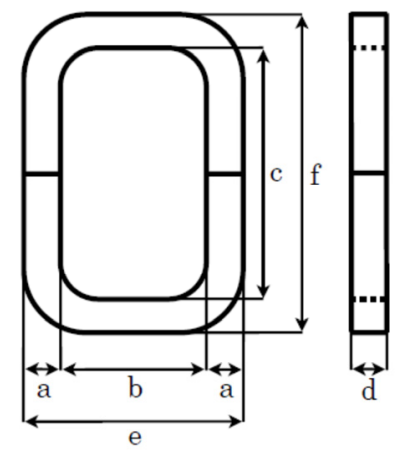

Fig. 16. Inductor core dimensions.

between winding regions 2 and 3 and the aluminum can. Dimensions $l_{c-w l}-l_{c-w 4}$ denote the spacings between winding regions 1 and 4 and the core, respectively. Dimensions $l_{h s-w l^{-}}$ $l_{h s-w 4}$ denote the spacings between winding regions $1-4$ and the edges of the heat spreader. $l_{w 2-c a n, y}, l_{w 2-c a n, z}$, and $l_{w 3-c a n, x}$ denote the spacings between winding regions 2 and 3 and the can, in the $y$ - and $z$-axes, and the $x$-axis, respectively. $N_{t}, t_{C u}, T_{i}, K_{w}$, and $T_{h s}$ denote the number of turns, the thickness of each turn (copper foil), the thickness of each layer of insulation material (Kapton film), the winding factor and the thickness of the heat spreader tile, respectively. $\kappa_{c, y}, \kappa_{c, z}, \kappa_{h s}$, and $\kappa_{p o t}$ denote the thermal conductivities of the core in the $y$-and $z$-axes, the heat spreader tile, and the potting compound, respectively.

\section{REFERENCES}

[1] J. W. Kolar, J. Biela, S. Waffler, T. Friedli, and U. Badstuebner, "Performance trends and limitations of power electronic systems," in Proc.ECPE- CIPS, Nuremberg, Germany, 2010.

[2] J. Scoltock, G. Calderon-Lopez, Y. Wang, and A. J. Forsyth, "Design optimization and trade-offs in multi-kW DC-DC converters," in Proc. IEEE-ECCE, Milwaukee, WI, USA, 2016.

[3] T. M. Andersen, F. Krismer, J. W. Kolar, T. Toifl, C. Menolfi, L. Kull, T. Morf, M. Kossel, M. Brändli, and P. A. Francese, "Modeling and Pareto Optimization of On-Chip Switched Capacitor Converters," IEEE Trans. Power Electron., vol. 32, pp. 363-377, 2017. DOI: 10.1109/TPEL. 2016.2529501.

[4] R. M. Burkart and J. W. Kolar, "Comparative $\eta-\rho-\sigma$ Pareto Optimization of $\mathrm{Si}$ and $\mathrm{SiC}$ Multilevel Dual-Active-Bridge Topologies With Wide Input Voltage Range," IEEE Trans. Power Electron., vol. 32, pp. 5258-5270, 2017. DOI: 10.1109/TPEL.2016.2614139.

[5] J. W. Kolar, D. Bortis, and D. Neumayr, "The ideal switch is not enough," in IEEE-ISPSD, Prague, Czech Republic, 2016.

[6] N. Simpson, R. Wrobel, and P. H. Mellor, "An Accurate Mesh-Based Equivalent Circuit Approach to Thermal Modeling," IEEE Trans. Magn., vol. 50, pp. 269-272, 2014. DOI: 10.1109/TMAG.2013.2282047.

[7] R. Wrobel, N. McNeill, and P. H. Mellor, "Performance Analysis and Thermal Modeling of a High-Energy-Density Prebiased Inductor," IEEE Trans. Ind. Electron., vol. 57, pp. 201-208, 2010. DOI: 10.1109/ TIE.2009.2029518

[8] R. Wrobel and P. H. Mellor, "A General Cuboidal Element for Three-Dimensional Thermal Modelling," IEEE Trans. Magn., vol. 46, pp. 3197-3200, 2010. DOI: 10.1109/TMAG.2010.2043928.

[9] N. Simpson, R. Wrobel, and P. H. Mellor, "A General Arc-Segment Element for Three-Dimensional Thermal Modeling," IEEE Trans. Magn., vol. 50, pp. 265-268, 2014. DOI: 10.1109/TMAG.2013.2278866.

[10] M. Leibl, G. Ortiz, and J. W. Kolar, "Design and Experimental Analysis of a Medium-Frequency Transformer for Solid-State Transformer Applications," IEEE Trans. Emerg. Sel. Topics Power Electron., vol. 5, pp. 110-123, 2017. DOI: 10.1109/JESTPE.2016.2623679.

[11] Y. Liu, K. See, S. Yin, R. Simanjorang, C. F. Tong, A. Nawawi, and J. J. Lai, "LCL Filter Design of a 50-kW 60-kHz SiC Inverter with Size and Thermal Considerations for Aerospace Applications," IEEE Trans. Ind. Electron., vol. 64, pp. 8321-8333, 2017. doi: 10.1109/TIE.2017.2677338.
[12] G. M. Shane and S. D. Sudhoff, "Design Paradigm for Permanent-Magnet-Inductor-Based Power Converters," IEEE Trans. Energy Convers., vol. 28, pp. 880-893, 2013. DOI: 10.1109/ TEC.2013.2274476.

[13] Hitachi Metals, "Metglas AMCC series cut Core/Finemet F3CC series cut core," Catalog No. HJ-B11. [Online]. Available: http://www.hitachimetals.co.jp/products/elec/tel/pdf/hj-b11.pdf. Accessed on: Jun. 2019.

[14] Vacuumschmelze, "Nanocrystalline Cut Cores," [online]. Available: https://www.vacuumschmelze.com/Products/Inductive-Components-and -Cores/Cut-Cores. Accessed on: Jun. 2019.

[15] G. Calderon-Lopez and A. J. Forsyth, "High power density DC-DC converter with SiC MOSFETs for electric vehicles," in Proc. IET-PEMD Manchester, U.K., 2014.

[16] Y. Wang, G. Calderon-Lopez, and A. J. Forsyth, "High-Frequency Gap Losses in Nanocrystalline Cores," IEEE Trans. Power Electron., vol. 32, pp. 4683-4690, 2017. DOI: 10.1109/TPEL.2016.2594083.

[17] H. Fukunaga, T. Eguchi, T. Mita, Y. Ohta, and H. Kakehasi, "Reduction in Core Loss in Amorphous Cut Cores with Air Gaps," IEEE Transl. J. Magn. Jpn, vol. 5, pp. 626-632, August 1990. DOI: 10.1109/ TJMJ.1990.4564311.

[18] Y. Wang, G. Calderon-Lopez, and A. Forsyth, "Thermal Management of Compact Nanocrystalline Inductors for Power Dense Converters," in Proc. IEEE-APEC, San Antonio, TX, USA, 2018.

[19] R. Jez, "Influence of the Distributed Air Gap on the Parameters of an Industrial Inductor," IEEE Trans. Magn., vol. 53, pp. 1-5, 2017. DOI: 10.1109/TMAG.2017.2699120.

[20] S. Nogawa, et al., "Study of Eddy-Current Loss Reduction by Slit in Reactor Core," IEEE Trans. Magn., vol. 41, pp. 2024-2027, May 2005. DOI: 10.1109/TMAG.2005.846267.

[21] G. Calderon-Lopez, Y. Wang, and A. J. Forsyth, "Mitigation of Gap Losses in Nanocrystalline Tape-Wound Cores," IEEE Trans. Power Electron., vol. 34, pp. 4656-4664, 2019. DOI: 10.1109/ TPEL.2018.2863665.

[22] B. W. Carsten, "Reconfiguring Tape Wound Cores for Inductors". U.S. Patent Application US 2013/0257578 A1, Oct. 3, 2013.

[23] T. Tera, H. Taki, and T. Shimizu, "Loss Reduction of Laminated Core Inductor used in On-board Charger for EVs," IEEJ Journal of Industry Applications, vol. 4, pp. 626-633, 2015. DOI: 10.1541/IEEJJIA.4.626.

[24] B. W. Carsten, "Inductor Core Shaping near an Air Gap" U.S. Patent 8,466,766 B2, Jun. 18, 2013

[25] B. Cougo, A. Tüysüz, J. Mühlethaler, and J. W. Kolar, "Increase of tape wound core losses due to interlamination short circuits and orthogonal flux components," in Proc. IEEE-IECON, Melbourne, VIC, 2011. pp. 1372-1377.

[26] N. Kondrath and M. K. Kazimierczuk, "Inductor winding loss owing to skin and proximity effects including harmonics in non-isolated pulse-width modulated dc-dc converters operating in continuous conduction mode," IET Power Electronics, vol. 3, pp. 989-1000, 2010. DOI: 10.1049/iet-pel.2009.0299.

[27] A. Van den Bossche and V. C. Valchev, Inductors and Transformers for Power Electronics. Boca Raton, FL, CRC Press, 2005.

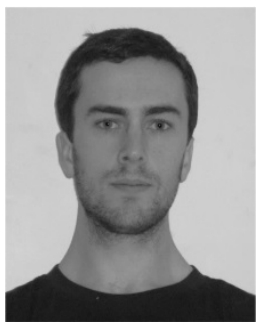

James Scoltock (S'09-M'15) received the B.E. (Hons) and Ph.D. degrees, both in electrical and electronic engineering, from the University of Auckland, New Zealand, in 2009 and 2015, respectively. He was a Research Associate in the School of Electrical and Electronic Engineering, the University of Manchester, U.K., from 2015 until 2017. He is currently a Research Associate in the Department of Electronic and Electrical Engineering, the University of Sheffield, U.K. His research interests include power electronics, electrical drives, model predictive control, and energy storage and management. 


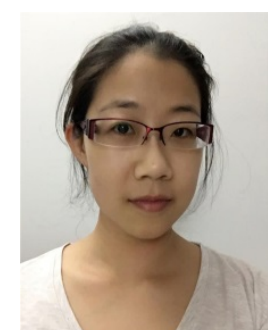

Yiren Wang received the B.Eng.(Hons.) degree in electrical and electronic engineering from The University of Manchester, Manchester, U.K. and North China Electric Power University, Baoding, China, in 2011, and the Ph.D. degree in power electronics from The University of Manchester, U.K., in 2015.

She was a Research Associate at The University of Manchester from 2016 to 2018. She is currently a Power Electronic Design Engineer at Zytek Automotive/Continental Engineering Services, U.K. Her research interests include magnetic components for high power density DC-DC converters, modeling, design and optimisation.

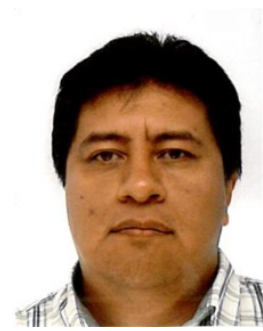

Gerardo Calderon-Lopez received the degree of ing. en comunicaciones y electrónica from the National Polytechnic Institute (IPN), Mexico City in 1999, the M.Sc. in power electronics and drives from The Universities of Birmingham and Nottingham, U.K. in 2001, and the Ph. D. degree in power electronics from The University of Manchester, U.K. in 2009.

$\mathrm{He}$ is a Research Associate at The University of Manchester. His research interests include power-dense converters and magnetic components.

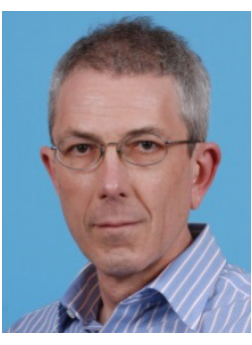

Andrew J. Forsyth (M'98) received the B.Sc.(Eng) degree in Electrical Engineering from Imperial College, London, U.K., in 1981 and the Ph.D. degree in Power Electronics from the University of Cambridge, Cambridge, U.K., in 1987.

He was a Design Engineer with GEC Electrical Projects Ltd from 1981 to 1983, a Lecturer at the University of Bath from 1986-1990, and a Lecturer / Senior Lecturer at Birmingham University from 1991 to 2004. Since 2004 he has been Professor of Power Electronics at the University of Manchester, Manchester U.K. His research interests include high-frequency converters and magnetic components, converter modelling and control, aerospace and electric vehicle applications. 